\title{
Tectonic and kinematic study of a strike-slip zone along the southern margin of Central Ovda Regio, Venus: Geodynamical implications for crustal plateaux formation and evolution
}

\author{
Ignacio Romeo $^{\mathrm{a}, *}$, Ramón Capote ${ }^{\mathrm{a}}$, Francisco Anguita ${ }^{\mathrm{b}}$ \\ a Departamento de Geodinámica, Facultad de Ciencias Geológicas, Universidad Complutense, Madrid, Spain \\ ${ }^{\mathrm{b}}$ Departamento de Petrología y Geoquímica, Facultad de Ciencias Geológicas, Universidad Complutense, Madrid, Spain
}

\begin{abstract}
The tectonic system of the southern margin of Central Ovda Regio, a crustal plateau which straddles Venus equator, has been interpreted as a dextral strike-slip array, on the basis of evidence clearly identifiable, as are Riedel fracture patterns of different scales, en échelon folds and brittle strike-slip faults. This transcurrent regime developed two main shear belts (Inner and Outer, on respectively thicker and thinner crust), whose minimum dextral displacement has been estimated in 30-50 km. Since the up or downwelling models for plateau formation cannot easily explain tectonic shears of this magnitude along their margins, an alternative hypothesis has been built, which stands on the proposed collisional belt which could form Ovda northern border (King et al., 1998, Lunar Planet. Sci. Conf. 29, Abstract 1209; Tuckwell and Ghail, 2002, Lunar Planet. Sci. Conf. 33, Abstract 1566). Within this framework, the shear would represent a transcollisional transcurrent zone, similar to the strike-slip zones produced in the foreland of the Himalayas-Tibet collision front. Eastern Ovda would be an independent area of thickened crust, pushed to the SSE by the northern collision, with the deformation concentrated at its margins, and experiencing a shear strain on its southern margin. None of the data, however, either supports nor helps to discard theoretical subduction events as a cause of the collision. On the contrary, image relationships could be interpreted as evidence that the main shear deformation took place during the last global resurfacing event on the planet.
\end{abstract}

Keywords: Venus; Tectonics

\section{Introduction}

Contrasting with the relatively well understood Mercury, Moon and Mars, Venus has become the main ground test for geodynamic theories on the inner workings of terrestrial planets. The evidence for a massive, active volcanism, along with the absence of traceable plate borders, has lead to a general agreement that the geology of Venus is the result of hotspot tectonics. Within this general framework, crustal plateaux (continent-sized regions of thickened crust and a high density of tectonic structures) are interpreted ei- ther as mantle upwellings or downwellings, a controversy that reflects our poor understanding of the planet dynamics. Beyond this doubt, a critical question remains: can all the tectonic structures, on the plateaux and elsewhere on the planet, be explained away as a consequence of vertical mantle dynamics?

Ovda Regio, the western part of Aphrodite Terra, is the largest crustal plateau on Venus. Ovda straddles the planet Equator from $50^{\circ} \mathrm{E}$ to $110^{\circ} \mathrm{E}$ and from $5^{\circ} \mathrm{N}$ to $15^{\circ} \mathrm{S}$, covering $1.5 \times 10^{7} \mathrm{~km}^{2}$. It features a core of basin and dome tesserae (complex tectonic terrains with several sets of structures cross-cutting at high angles), a northern, $500 \mathrm{~km}$ wide band showing signs of intense contraction (lineated tesserae), and intratessera volcanic plains flooding the topo- 
graphic depressions. Like other crustal plateaux, Ovda Regio has been interpreted by most authors (Phillips and Hansen, 1998; Hansen et al., 1997, 1999; Ghent and Hansen, 1999) as the result of an upwelling mantle flow impinging on a thin crust: first, a plume reaches the crust-mantle boundary, forming a dome crossed by radial ribbons (Ghent and Hansen (1998), and Hansen and Willis (1997, 1998), see under); then the dome collapses laterally, and fold belts are formed at the margins; last, the crust relaxes generating radial graben. Other authors (Bindschadler et al., 1992) propose on the contrary that crustal plateaux formed by the thickening and shortening of the lower ductile crust over a cold spot. This downwelling flow would first induce a compressional stress field, then a terminal, tensional field caused by the collapse of the thickened crust. A third model (Tuckwell and Ghail, 2002), affecting only the eastern part of Ovda, comprises a collision from the north (previously proposed by King et al. (1998)) and a simultaneous hot spot in the center of Eastern Ovda.

The structural and kinematic analysis we have performed on the southern margin of ovda Regio is pertinent on this controversy, since we have found a tectonic pattern that can be interpreted as caused by a dextral strike-slip deformation along the margin trend, a hypothesis that will be tested in this paper. This interpretation does not fit into the most accepted upwelling model, as will be discussed in this paper. The cold spot model can neither explain a strike-slip tectonics of this magnitude. On the contrary, this shear tectonics is coherent with the advocated collision in the northern margin of Eastern Ovda (King et al., 1998; Tuckwell and Ghail, 2002), as it can be explained as the effect of a strike-slip zone located in a transcollisional geodynamic setting.

\section{Structural analysis}

The study area is located between $6^{\bullet}-16^{\bullet} \mathrm{S}$ and $78^{\bullet}-$ $86^{\circ} \mathrm{E}$. Although it was included in more general works (Ivanov and Head, 1996; Ghent and Hansen, 1999) a detailed structural analysis had not been carried out so far. Trough the study of FMIDR, $75 \mathrm{~m} /$ pixel images of the southern margin of Central Ovda Regio (both right and left-looking, and stereo pairs), we have defined a strike-slip tectonic regime (Romeo et al., 2003) in which the shear deformation is accommodated by three types of structures: folds of different wavelength, normal faults usually forming narrow graben (ribbons), and strike-slip faults.

The proposed dexral strike-slip hypothesis for explaining the main structural pattern observed in the southern margin of Central Ovda has been built after the compilation of a large number of single observations. A number of consistent arguments have allowed to build up a simple comprehensive and coherent picture of the strain history.

Ghent and Hansen (1998), and Hansen and Willis (1997, 1998) defined ribbon terrains as zones that feature alternat- ing dark and bright large $(>50 \mathrm{~km})$ lineaments spaced 1 to $4 \mathrm{~km}$. This pattern, which seems to be produced by troughs and ridges separated by opposite scarps, has been interpreted (Hansen and Willis, 1997, 1998) as the result of the extension of a very thin brittle layer over a ductile decollement. By analogy with boudinage (Mandal et al., 2000), two types of ribbons have been defined (Ghent and Hansen, 1998): shear-fracture, and tensile-fracture. Tensile-fracture ribbons are defined (Ghent and Hansen, 1998) by the opening of an extensional fracture, so in this case the floor of the ribbon trough corresponds to the outcropped ductile decollement. The viability of forming these structures has been discussed by Gilmore et al. (1998) using thermal constraints. Shearfracture ribbons are defined (Ghent and Hansen, 1998) as long narrow graben where the floor of the trough ramp up to the top of the adjacent horst in the ribbon termination.

In the southern margin of Central Ovda Regio we have found shear-fracture ribbons only, with multiple scarps and open terminations, and no evidence of tensile-fracture ribbons. So in this paper we will use the term ribbon as a synonym for a large narrow graben (shear-fracture ribbon with the terminology of Ghent and Hansen, 1998).

The analyzed area is an elongated strip located between the plateau central zone, characterized by a basin and dome interference structural pattern (Ghent and Hansen, 1997, 1999), and the Aino Planitia volcanic plain. In the topographic profile perpendicular to Central Ovda southern margin, the minimum height is located in the contact between the Ovda tessera terrains and the Aino planitia lavas. From this minimum the topography raises abruptly towards the north to the Ovda plateau, but raises very gently to the south, reaching gradually the medium level of Aino planitia. We consider that at least part, if not all, of this depression is originated by the flexure of the crust of Aino Planitia caused by the weight of the thickened crust of Ovda.

The structural analysis performed in this study allows us to divide the deformation shear belt in two different tectonic domains (Fig. 1): the Inner Shear Belt (ISB) where the strike-slip deformation is accommodated by en échelon folds and perpendicular ribbons, and the Outer Shear Belt (OSB) where it is accomplished by strike-slip faults and en échelon sigmoidal ridges. The complete description of each tectonic domain can be found below.

\subsection{The inner shear belt}

Located between $8^{\bullet}-12^{\bullet} \mathrm{S}$ and $78^{\bullet}-86^{\bullet}$ E, this $200 \mathrm{~km}$ wide tectonic domain features two main, perpendicular sets of structures: folds and ribbons. The folds are arranged in an en échelon right-stepped pattern which trends $N 77^{\circ}$, clearly oblique to the margin direction $\left(\mathrm{N}^{100^{\bullet}}\right.$ to $\left.1 \mathbf{1}^{\circ}\right)$. The fold interpretation is supported by (1) the gradual variation of radar brightness across the traces of the structures (Ghent and Hansen, 1999), and (2) the flooding of some onlapping in ratessera volcanic plains, which clearly marks periclinal terminations. Some inter-anticline valleys appear flooded by 

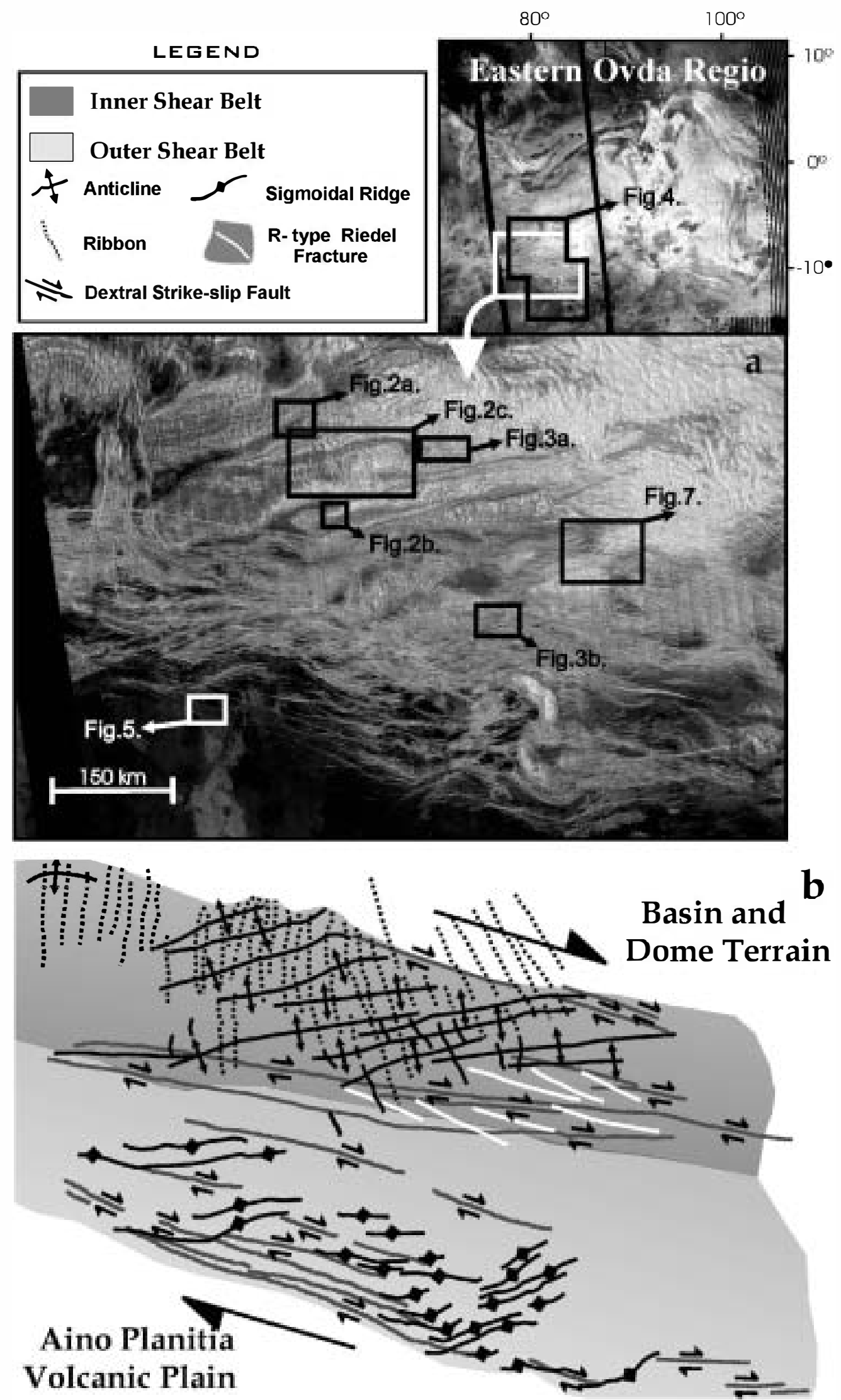

Fig. 1. Schematic tectonic map of the Southern Margin of Central Ovda, with the main structural characteristics of both the Inner and the Outer Shear Belts. Due to the small scale, every lineation represents several individual structures. The location of Figs. 2-5 and 7 is indicated. 
dark intratessera volcanic plains that show inlier textures with tessera terrains. These elongated in atessera plains are cut by large $(>300 \mathrm{~km})$ lineaments of unclear origin, parallel to the anticline axial traces, which could be interpreted as reverse faults associated with the folds, a hypothesis supported by their irregular traces. The mean spacing between anticlinal axial races ranges from 15 to $40 \mathrm{~km}$. Taking into account, though, that the anticlines are wider than the interanticline valleys, as well as the existence of probable reverse faults, this spacing could be smaller than the real folding wavelength.

All the en échelon folds finish against a large lineament trending parallel to the plateau margin in the north of the fold set. The fact that some of the folds show torsions interpretable as dextral drags towards this lineament, and the evidence of dextral displacement of previous structures (a set of NE-SW ribbons, see Fig. 3a), supports an interpretation of this lineament as a ductile dextral strike-slip fault. Towards the south the en échelon set of anticlines is limited by large brittle faults also parallel to the plateau boundary that characterize the OSB. We interpret these large lineaments as dextral strike-slip faults, and the evidence for this interpretation is discussed below (see the Outer Shear Belt).

A very penetrative ribbon fabric $\left(\mathrm{N} 167^{\circ}\right)$ perpendicular to the set of en échelon anticlines completes the structural pattern of the ISB. Assuming that the folds are pure contractional structures normal to the shortening axis $\left(\mathrm{N} 167^{\circ}\right)$, and that the ribbons are pure extensional structures developed along the shortening direction, it would follow that both structures are coherent with the same stress field. Similar tessera tectonic patterns have been described (King et al., 1998; Ghent and Hansen, 1997, 1999) in the northem and northeastern margins of Eastern ovda Regio, a structural pattern that indicates a contractional deformation with perpendicular stretching. The folding in those margins is nevertheless parallel to the plateau limits, while on the southern margin of Central ovda the folding is oblique to the margin trend showing a right-stepped en échelon pattern of the folds, a fact that implies a relative dextral movement along the plateau boundary.

Two opposite hypotheses to explain the origin of the fold and ribbon terrain. Hansen and Willis (1995, 1998), Phillips and Hansen (1998), Ghent and Hansen (1997, 1999), and Hansen et al. $(1997,1999)$ consider that the ribbons predate the folds, while Gilmore et al. (1998), and Ivanov and Head (1999) propose that the folds are the first-formed structures and that the ribbons were formed simultaneously, and also after the folds, but not before them. As for the mechanics of the deformation, Hansen and Willis $(1995,1998)$, and Ghent and Hansen $(1997,1999)$ hypothesized that ribbons were formed by the extension of a very thin $(\sim 1 \mathrm{~km})$ brittle layer above a ductile substrate, thus explaining their small ( 2 to $4 \mathrm{~km}$ ) wavelength. This hypothesis assumes however that the decollement that constitutes the lower limit of the thin brittle layer is the brittle-ductile ransition (BDT), an implication that necessitates a very high thermal regime.
Gilmore et al. (1998) do not consider that this mechanical limit should be the BDT: With the present constraints, it could be located at any lithological limit within the brittle crustal domain

If the regional crust contains at least an internal decollement surface within the brittle domain (an assumption that would explain the narrowly spaced ribbons), this internal crustal limit should also develop contractional structures with a shorter wavelength than the described set of en échelon folds. This secondary structures, with a $2-10 \mathrm{~km}$ wavelength, can in fact be observed in the northwestern ISB (Fig. 2a) as ridges (secondary folds) parallel to the main en échelon folds. In this way, the ribbons and the secondary folds could be interpreted as formed under a unique stress field with a N167 ${ }^{\circ}$ shortening direction, through the contraction and perpendicular extension of the upper layer of the brittle crust. At the same time, the contractional deformation of the whole brittle crust produced the main set of en échelon folds.

Two different arguments implying that some ribbons postdate the folds have been put forward. Gilmore et al. (1998) have found that at least some ribbons are wider at the fold crests than at their flanks. We have found this same structural relation in the ISB (Fig. 2b), so at least these ribbons were formed after the folding. We have considered the foreshortening radar artifact (Connors, 1995; Farr, 1993) suffered by the ribbons that cross the folds, but even taking into account this effect these ribbons seem to be wider at the fold crests. Other ribbons of the same set do not show nevertheless this spatial relationship, which could mean that ribbon formation was simultaneous with the folding, but also that it continued after it

Additional evidence implying that some ribbons were formed after the folding is that an intratessera volcanic plain located in an inter-fold valley is crossed by some ribbons but not by others (Fig. 2c). Similar structural relationships have been shown by Ivanov and Head (1999) in the northeastern margin of Ovda, although Ghent and Hansen (1999) consider that the existence of that volcanic unit is not supported by the observations, inasmuch as it could be a darker radar elongated area between two folds. We contend, however, that the existence of the post-folding intratessera volcanic unit showed in Fig. $2 \mathrm{c}$ is supported by their inlier textures onlapping over tesserae

\subsection{Other stress fields registered in the ISB}

The described tectonic stage does not account for every structure in the ISB, since there are structures clearly formed before and after the dextral shearing, and which therefore define different strain fields. The oldest of these is a set of ribbons rending $\mathrm{N} 30^{\bullet}$ to $55^{\bullet}$ covered by a volcanic unit which was sheared during the main tectonic stage developing N167 ribbons. If the ribbons were pure extensional structures, a NE-SW shortening direction could be deduced. This old ribbon set can be used as a marker of the dextral 

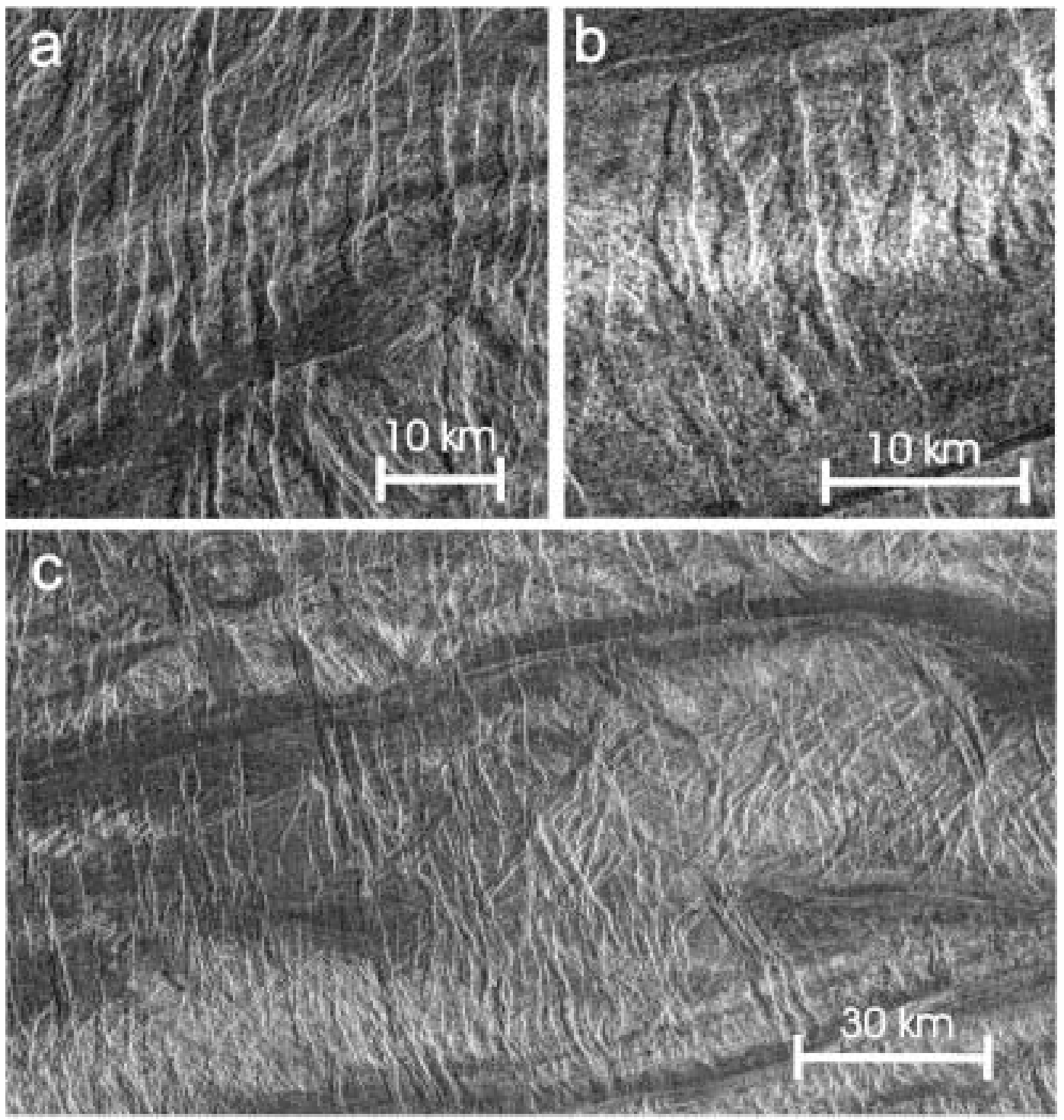

Fig. 2. (a) Ribbons trending N-S and ridges of a similar wavelength trending NE-SW. (b) A previous fold crossed by ribbons that appear wider at the folds crest than at their flanks. (c) Ribbons crosscutting a post-folding intratessera volcanic plain that shows inlier textures with the tessera terrain of the fold. Locations are shown in Fig. 1

strike-slip fault that limits the ISB to the north (Fig. 3a). This fault does not affect significantly the shearing-related ribbon set, which indicates that this transcurrent structure was formed during the first stages of the shearing. The fault concentrated the regional deformation, thus limiting the development of the en échelon folds to the north, but its movement ceased before the formation of the shearing-related set of ribbons.

The last tectonic stage recorded in the ISB is represented by two sets of structures, a $\mathrm{N} 40^{\circ}-50^{\circ}$ ribbon set and a $\mathrm{N} 135^{\circ}-140^{\circ}$ set of straight ridges, which cut a subcircular plain centered at $80^{\circ} \mathrm{E}-8^{\circ} \mathrm{S}$ and located between the dome and basin terrain and the ISB. Again assuming that ribbons are pure-extensional structures, and also that the ridges are pure-contractional structures, both sets of structures are coherent with a NE-SW compression.
To sum up, the complex strain evolution of the ISB includes three tectonic stages: a first one with a NE-SW azimuth, which formed the $\mathrm{N} 30^{\circ}$ to $55^{\circ}$ ribbons; the main, shearing stage with a NNW-SSE shortening azimuth, and finally a local, NE-SW shortening strain which produced the $\mathrm{N} 40^{\circ}-50^{\circ}$ ribbons and perpendicular ridges.

\subsection{The Outer Shear Belt}

This deformed strip is located immediately to the south of the ISB, at the plateau margin, an area of subdued topography which merges with Aino Planitia volcanic plains. The main, shearing tectonic stage produced in this area structures which contrast markedly with those of the inner belt. The dextral tectonic belt is formed by large $(>600 \mathrm{~km})$ straight bright lineaments with a subparallel trend to the margin di- 

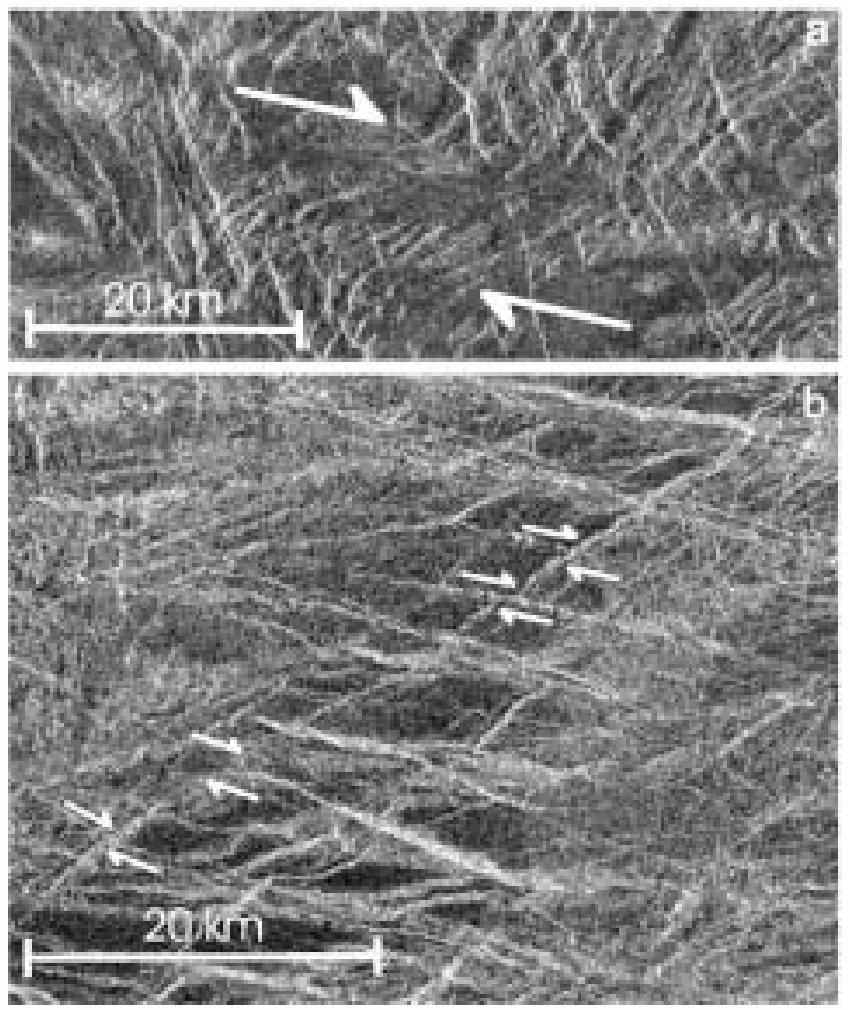

Fig. 3. Evidence of dextral displacement of previous structures. (a) Dextral offset of the NE-SW ribbon set accomplished by the narrow strike-slip band that limits the ISB to the north. This displacement is not a radar artifact caused by foreshortening because the NW-SE ribbon set that postdates the strike-slip movement of this narrow band does not show foreshortening. (b) Dextral displacement of the $\mathrm{N} 55^{\circ}$ lineament accommodated by the strike-slip faults of the OSB. This offset has been used for estimating the total dextral displacement of this belt. Locations are shown in Fig. 1.

rection $\left({\mathrm{N} 95^{\circ}}^{\circ}\right.$ to $\left.120^{\circ}\right)$, spaced $10-30 \mathrm{~km}$, and cutting the tessera terrains, the intratessera volcanic plains, and the regional volcanic plains of Aino Planitia (Fig. 4). The brightness of the lineaments is not typical of fault scarps: they correspond more probably to a damage fault zone, i.e., a dense fracture swarm which produces a high roughness band.

These structures show an internal anastomosing and rhomboidal fracture pattern (Fig. 5a), a tectonic feature very similar to the R-P Riedel systems ordinarily described in Earth strike-slip faults (Davis et al., 2000; Kim et al., 2003; Faulkner et al., 2003), and in experimental works as well (Ahlgren, 2001; Ferill et al., 1997; Tchalenko, 1970). In detail, the faults feature a set of en échelon fractures trending $\mathrm{N} 125^{\circ}$ that we interpret as R-type Riedel fractures, and a less developed set of fractures trending $\mathrm{N} 93^{\circ}$ that can be identified as P-type Riedel fractures (Fig. 5b). This tectonic pattern points to an evolved Riedel zone (Ahlgren, 2001), which is expected to develop as first a set of en échelon Rtype fractures, later connected by $\mathrm{R}^{\prime}$-type fractures. P-type fractures would be generated at the closing stage (Fig. 5c). $\mathrm{R}^{\prime}$-type fractures have not been observed, probably because these are expected to be short structures and therefore may lie beyond the resolution.
The R-P Riedel fracture pattern interpretation provides support for our hypothesis that these strike-slip faults are dextral shears. The contrary hypothesis has nevertheless been considered because the Riedel model establishes that $\mathrm{R}$ and $\mathrm{P}$ fractures are formed at the same angle $\left(=45^{\circ}-\Phi / 2\right.$, being $\Phi$ the internal friction) to the fault trace. Thus, the set of $\mathrm{N} 125^{\circ}$-trending fractures could be the P-type set and the set trending $\mathrm{N} 93^{\circ}$ could be the R-type set, which would imply a sinistral movement. We have finally rejected this interpretation because the $\mathrm{N} 125^{\circ}$ fracture set is more developed (i.e., it shows more fractures) than the $\mathrm{N} 93^{\circ}$ fracture set, and the experimental works indicate that $\mathrm{R}$ fractures always dominate over P fractures (Tchalenko, 1970; Ahlgren, 2001). This is not however a strong argument considering that the $\mathrm{N} 3^{\circ}$ fracture set is oriented near the radar beam direction which implies a low backscatter return, so the development of this set could be underestimated because of the radar characteristics.

The dextral shearing interpretation is moreover coherent with the structural pattern observed in the ISB, and with the other movement criteria found in the OSB. The Riedel patterns are not broken by the faults, which indicates that these have a small slip.

The second main structures of the OSB are en échelon sigmoidal ridges, more frequent between the described strike-slip faults. These ridges have smaller wavelengths (2$5 \mathrm{~km})$ than the en échelon folds of the ISB $(>15-40 \mathrm{~km})$, but their trends are coherent $\left(\left(\mathrm{N} 60^{\circ}-90^{\circ}\right)\right.$ and $\left(\mathrm{N} 77^{\circ}\right)$ respectively) with a unique strain field which shortened Southern Ovda Regio with a NNW-SSE direction, again assuming that both are pure-contractional structures. The ridges show sigmoidal shapes, and become asymptotic to the large strikeslip faults (Fig. 4). This sigmoidal geometry could be due to a dextral drag caused by the movement of the large strikeslip faults or due to the pre-existence of the faults acting as a mechanical forcing during the formation of the ridges.

This structural pattern featuring large strike-slip faults and sigmoidal ridges should be distinguished from the S-C terrains described in Ishtar Terra (Hansen, 1992) which denote a more ductile crustal behavior. The $\mathrm{C}$ lineaments in the S-C terrain of Itzpapalotl Tessera are ductile transcurrent bands with ridge morphology (Hansen, 1992). Those structures are very different to the strike-slip faults with Riedel fracture patterns present in the southern margin of Central Ovda Regio, which correspond to a more brittle crustal behavior. In addition to the faults and ridges, some narrow lineaments trending $\mathrm{N} 80^{\circ}$ complete the structural pattern. Since they are roughly parallel to the sigmoidal ridges, i.e., perpendicular to the shortening direction, we consider the interpretation of these structures as reverse faults the more probable, and consequently we have mapped these lineaments together with the sigmoidal ridges, although their traces are straighter. In all, the dynamics of the OSB can be synthesized in a distributed dextral shear, most of whose displacement is being absorbed by the large strike-slip faults 


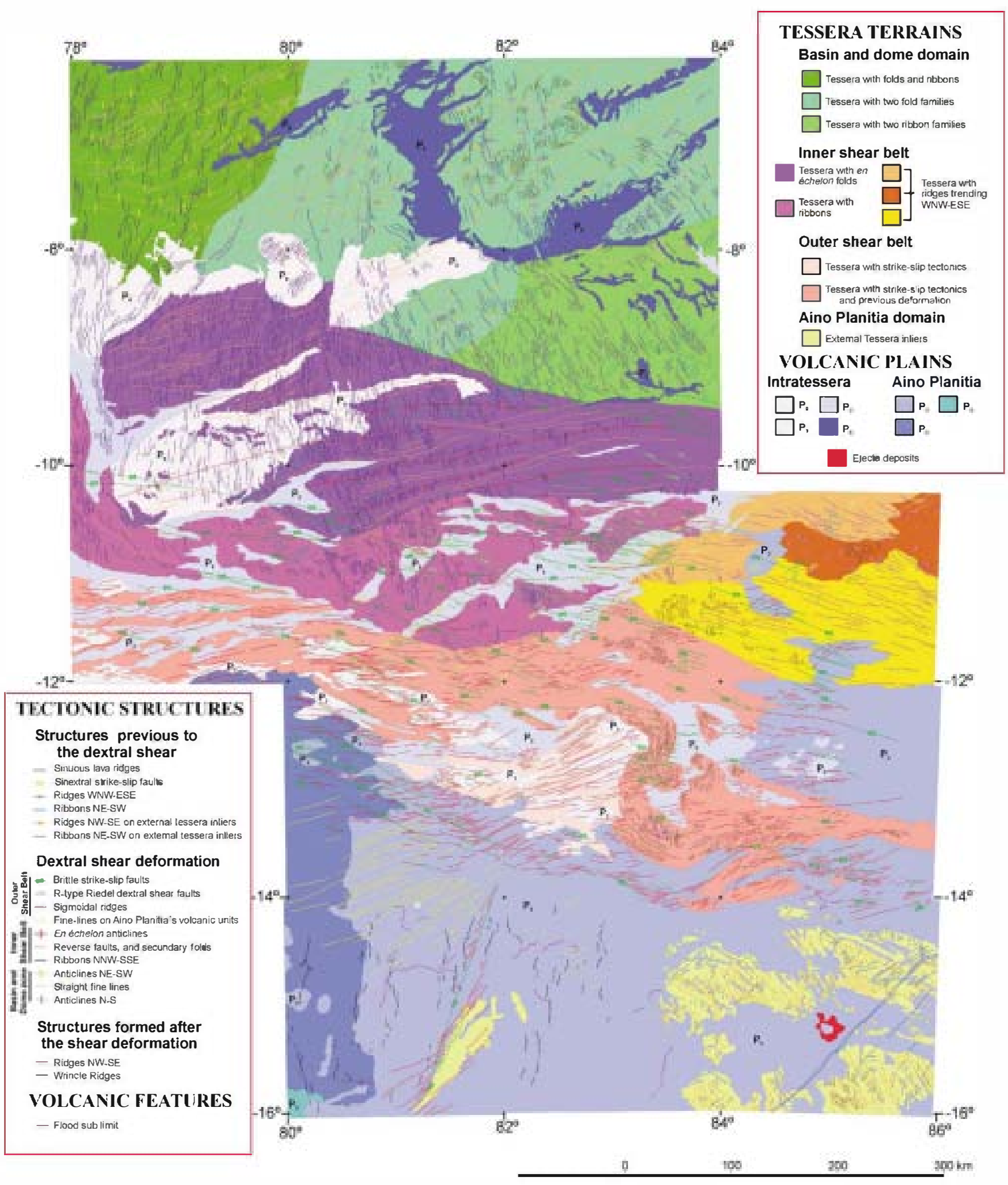

Fig. 4. Geological and structural cartography across the southern margin of Central Ovda. Tessera terrains have been distinguished with morphostructural criteria, consequently they do not correspond to lithological units rather they are morphostructural domains, zones characterized by different groups of structures. The volcanic units have been differentiated according to their roughness and with chronological criteria deduced by the cross-cutting relationships between them. The order of the volcanic units flooding is first $\mathrm{P}_{0}$ and the last $\mathrm{P}_{6}$. The tectonic structures have been separated in different tectonic stages for an easier comprehension. Regional location is shown in Fig. 1. 


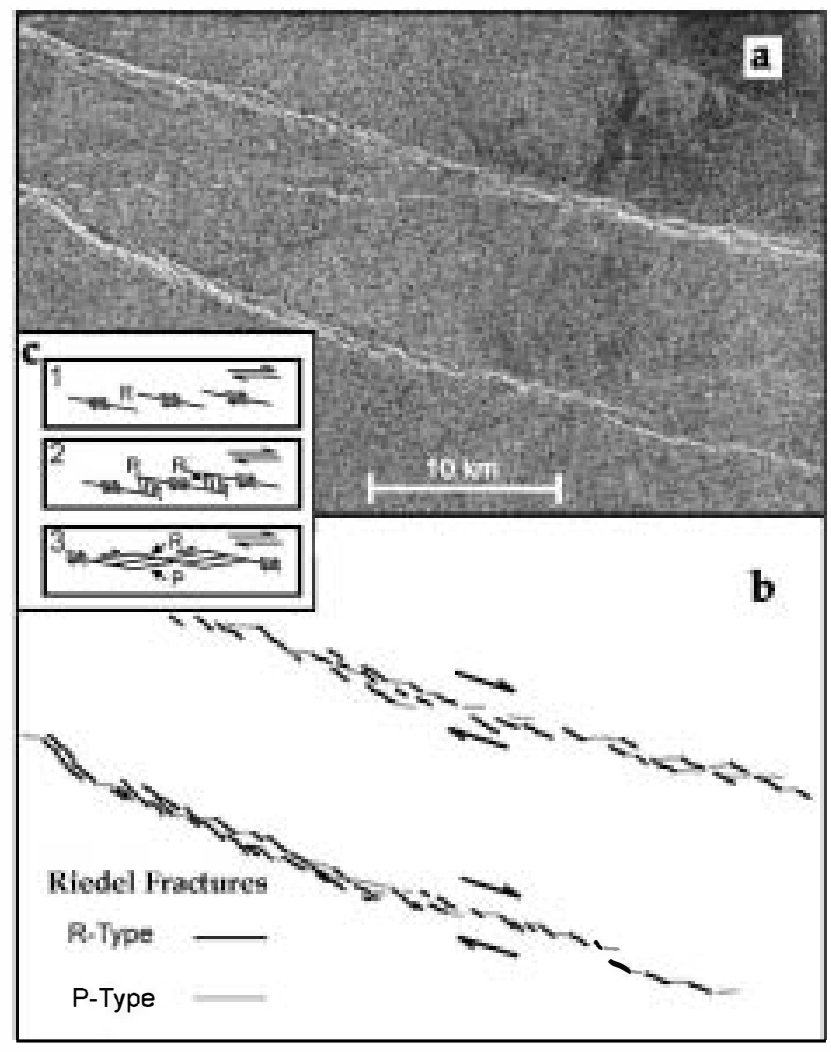

Fig. 5. (a) Full-resolution left-looking Magellan image of the strike-slip faults developed across Aino Planitia. Location is shown in Fig. 1. Fault zone shows an internal rhomboidal fracture pattern. (b) Interpretation of the fracture design as an R-P Riedel fracture system. (c) Development of a Riedel fracture zone (Ahlgren, 2001): first en échelon R-type fractures are generated (1), then $\mathrm{R}^{\prime}$-type fractures (2), and finally $\mathrm{P}^{\prime}$-type fractures (3).

along the margin trend, and in a lesser degree by the transpressive deformation of the inter-strike-slip fault domains.

The trends of the strike-slip faults change from $\mathrm{N} 110^{\circ}$ in the west of the belt to $\mathrm{N}^{\circ} 5^{\circ}$ in the east, thus forming an arch parallel to the plateau margin. The perpendicular to the faults would ideally coincide in their Euler pole (Fig. 6), (Gordon et al., 1984) or the center of the relative rotational movement followed by Eastern Ovda with respect to Aino Planitia during the shear band formation.

\subsection{Other stress fields registered in the OSB}

The OSB also records other strain fields different from, and previous to, the dextral shearing. The area between $84^{\circ}-86^{\circ} \mathrm{E}$ and $10^{\circ}-12^{\circ} \mathrm{S}$ shows ridges trending $\mathrm{N} 110^{\circ}$, with $3-10 \mathrm{~km}$ wavelength and perpendicular, probably extensional fractures. If these ridges are folds perpendicular to $\sigma_{1}$, the stress field had a NNE-SSW shortening direction. In this same zone some straight structures trending $\mathrm{N} 55^{\circ}$ that extend to the southwest can also be observed. The largest trace is $>400 \mathrm{~km}$ long and crosses almost all the OSB. These straight lineaments show rhomboidal depressions limited by one scarp (Fig. 7) that we have interpreted as pull-apart basins. These basins provide a (sinistral) kine- matical criterion for the lineaments, so they are evidence for a set of sinistral strike-slip faults. This kinematics is also coherent with a NNE-SSW shortening direction. The N55 lineaments can be therefore considered as sinistral strike-slip faults formed simultaneously to the $\mathrm{N} 110^{\circ}$ ridges, both being responses to the same stress field. The $\mathrm{N} 55^{\circ}$ faults are cut and displaced, with a dextral offset (Fig. 3b), by the large strike-slip faults of the OSB. The largest fault of this set has been used as a marker to calculate the displacement in the OSB.

This group of structures $\left(\mathrm{N} 110^{\circ}\right.$ ridges with perpendicular fractures and $\mathrm{N}^{\circ} 5^{\circ}$ sinistral strike-slip faults) can be related to the $\mathrm{N} 30^{\circ}-55^{\circ}$ family of ribbons present in the ISB, which denotes a NE-SW compression. These two tectonic patterns, previous to the dextral shearing stage, seem to describe a radially distributed stress field with the principle stress axes trending away from the center of Eastern Ovda Regio.

No clear structural evidence has been found of a postshearing tectonic stage with a new different stress tensor, but considering that the OSB is situated in a region that links Ixel Chasma from the $\mathrm{W}$ and Kuanja Chasma from the E (Bleamaster and Hansen, 2004), it could be expected that this WNW-ESE chasmata system were registered in the OSB. The structures with a suitable orientation for an extensional reactivation are the brittle dextral strike-slip faults, that show the same direction as this extensional system. A possible feature related to this extensional reactivation could be the presence of pit chains, most of them located towards the east, where the Kuanja chasma influence is greater and the structures of both tectonic systems could be mixed. The origin of pit chains has been related to dikes at depth (Bleamaster and Hansen, 2001). Perhaps in this area the magma could intrude using previous discontinuities as are the strike-slip faults.

\subsection{The transition zone between the Inner and Outer Shear Belts}

Since both belts are kinematically equivalent, there is not a clear boundary between them. The transition zone features intratessera volcanic plains between elongated tessera outcrops trending $\mathrm{N} 70^{\circ}-80^{\circ}$ which are similar to the en échelon folds of the ISB (Fig. 4), and are cut by some brittle dextral strike-slip faults $\left(\mathrm{N} 95^{\circ}-100^{\circ}\right.$ trend, $40-50 \mathrm{~km}$ spacing, $>600 \mathrm{~km}$ long) typical of the OSB. Another set of $\mathrm{N} 110^{\circ}-$ $120^{\circ}$ lineaments appears between these strike-slip faults on the eastern area of the transition zone. We have interpreted this new set of faults as R-type Riedel fractures which implies a new dextral shear movement criterion.

The fact that even the volcanic plains that cover the valleys between the en échelon folds in the ISB are cut by the large dextral strike-slip faults (typical of the OSB) is a proof that the OSB formation posdates the ISB development. 


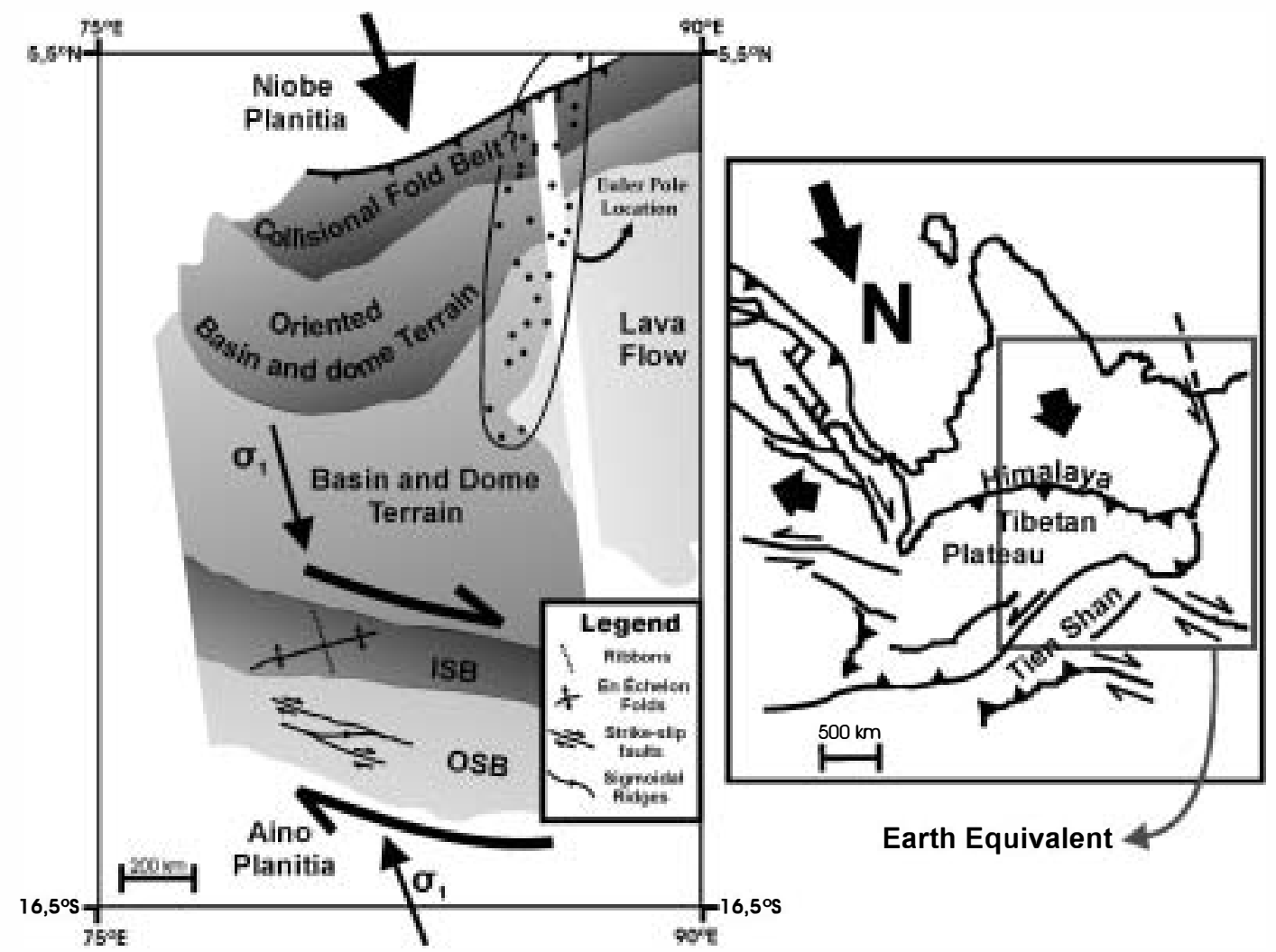

Fig. 6. Tectonic scheme of Central Ovda Regio showing a geodynamical interpretation of the shear zone located in the Southern Margin, as formed in a transcollisional setting in the foreland of the collisional belt described in the Northern Margin. Comparative scheme of the Himalayas collision, where similar strike-slip zones appear to the North of the Tibetan Plateau.

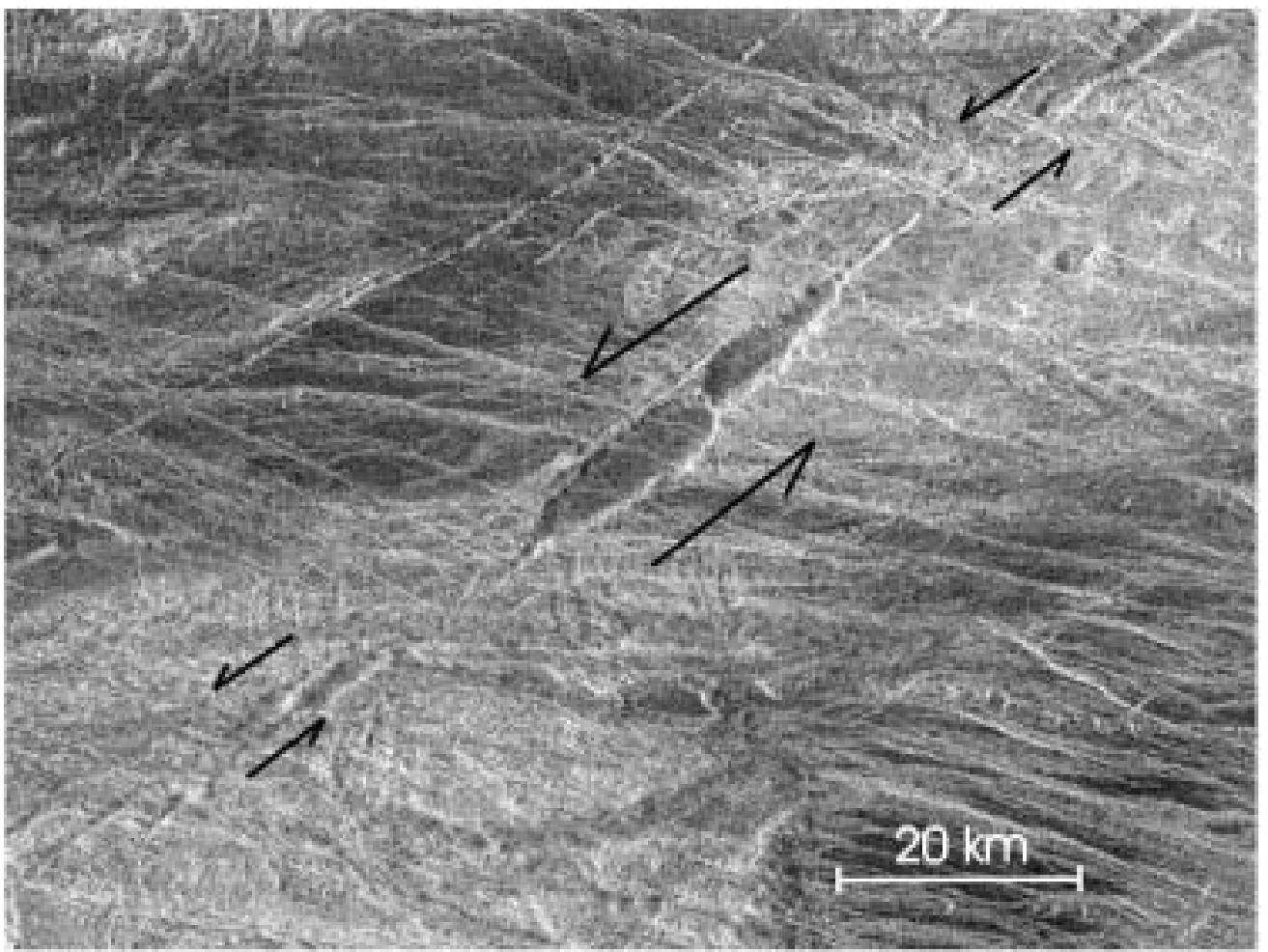

Fig. 7. Pull-apart basins developed along a $\mathrm{N} 55^{\circ}$ sinister strike-slip fault, this structure belongs to a pre-dextral-shearing tectonic stage. The pull-apart basins show different evolutive stages. Location is shown in Fig. 1. 


\section{Estimation of the displacement}

The dextral kinematics of both belts, ISB and OSB, is firmly supported by different observations: the en échelon disposition of the contractional structures (folds, sigmoidal ridges), the Riedel fracture patterns observed on the fault zone of the large strike-slip faults, the Riedel systems on a smaller scale (transition zone between the two belts), and the dextral displacement of previous straight structures.

\subsection{Inner Shear Belt dextral displacement}

The ISB is characterized by two main sets of structures: en échelon folds and perpendicular ribbons. The dextral horizontal shearing has been accommodated by both structures. Thus, knowing in detail the kinematics of each structure (i.e., the amount of shortening caused by the folds, and the quantity of extension produced by the perpendicular ribbons), the contribution of each set to the regional dextral shearing can be calculated. The component of each displacement vector parallel to the shear band is the amount of displacement accommodated by this structure, and can be deduced by simple trigonometry.

The very low amount of erosion on Venus (Campbell et al., 1997) permits an estimate of the kinematics of each structure by analysis of its topography. Morphostructural features have been determined through the analysis of Magellan images and altimetry data, though this last set of data does not have a resolution sufficient to resolve small structures, as are for instance ribbons.

\subsubsection{Contribution of the compressive structures to the shear}

Ghent and Hansen (1999) estimate the shortening occasioned through folding with the following expression:

$e=\frac{\lambda / 2-\sqrt{A^{2}+(\lambda / 2)^{2}}}{\sqrt{A^{2}+(\lambda / 2)^{2}}}$,

where $e$ is the fractional elongation (negative values indicating shortening), $A$ is fold amplitude, and $\lambda$ corresponds to fold wavelength. Equation (1) has been constructed assuming that the shortened layer maintained a constant thickness during shortening (parallel-style folding), and that there was no homogeneous layer shortening prior to the folding (Ghent and Hansen, 1999). Because it considers only the shortening accommodated by surface folding, shortening data calculated by Eq. (1) are minimum estimates (Burg and Podladchikov, 1999)

Fold amplitude corresponds to a half of the vertical distance from a synclinal axis to an anticlinal axis for the same folded layer. Assuming that the pre-folding ground surface was plain, this surface can be used to estimate fold amplitude. The difference in height between the anticline axis and one of the adjacent inflection lines can be used as an estimation of the fold amplitude. The data resolution of the
Table 1

Estimation of folding compression, and shear and transpressive components

\begin{tabular}{|c|c|c|c|c|c|}
\hline$A(\mathrm{~km})$ & $\lambda(\mathrm{km})$ & Elongation (\%) & $s(\mathrm{~km})$ & $s_{S}(\mathrm{~km})$ & $s_{t}(\mathrm{~km})$ \\
\hline \multirow[t]{2}{*}{0.4} & 20 & -1080 & 0.200 & 0.084 & 0.181 \\
\hline & 80 & $-\mathbf{0 . 0 0 5}$ & 0.012 & $\mathbf{0 . 0 0 5}$ & $\mathbf{0 . 0 1 1}$ \\
\hline \multirow[t]{2}{*}{1.2} & 20 & $-\bullet .712$ & 1.781 & 0.753 & 1.614 \\
\hline & 80 & $-\bullet .045$ & 0.112 & 0.048 & 0.102 \\
\hline
\end{tabular}

Magellan Altimetry Data is enough to grossly infer the fold amplitudes, that range between 400 and $1200 \mathrm{~m}$.

The values of wavelength are commonly measured directly on the images. As evidence of reverse faults between the en échelon anticlines has been found, the distance between fold races is shorter than their wavelength. Thus, another method to determine the wavelength of the en échelon folds should be used. Assuming that the anticline and syncline widths are equal, wavelength can be estimated as 2 times the anticline width, and measured as the distance between adjacent inflection lines. Magellan stereo pairs (Plaut, 1993) have been used to locate the inflection lines that separate anticline and syncline domains. The wavelengths measured with this method range between 20 and $80 \mathrm{~km}$. Using these values for $\lambda$ and $A$, Eq. (1) provides the results shown in Table 1

In this particular case the minimum shortening estimation provided by Eq. (1) is also an underestimate because it considers only the folding, i.e., the shortening produced by the probable reverse faults associated to the folds is not included in the calculus. That can explain the surprisingly low values of the shortening obtained with this method. These en échelon folds have very low values of $A$ with respect to $\lambda$, which implies that the accommodated shortening is low. This type of folding can be classified as "gentle" (Ramsay and Huber, 1987; Twiss and Moores, 1992; Ghent and Hansen, 1999)

The shortening $s$ caused by the folding imply a displacement, perpendicular to the fold trends (whose mean vector is N167') of Central Ovda Regio towards Aino Planitia. This vector can be broken down in two normal components (Eq. (2)): one parallel to the belt (shear component, $s_{s}$ ), and one perpendicular to the belt (ranspressive component, $s_{t}$ ):

$\vec{s}=\vec{s}_{s}+\vec{s}_{t}$.

The shear component of the displacement vector represents the contribution of the en échelon folds to the shearing. The larger, transpressive component expresses the amount of shortening perpendicular to the belt. The angle $(\boldsymbol{\alpha})$ between the direction perpendicular to the en échelon folds and the ISB trend has a value of $65^{\circ}$. Simple rigonome allows to calculate both components with the following expressions:

$s_{s}=s \cdot \cos \boldsymbol{\alpha}$,

$s_{t}=s \cdot \sin \boldsymbol{\alpha}$.

The results obtained for $s_{s}$ and $s_{t}$ are expressed in Table 1 for different values of $A$ and $\lambda$. The values of shortening are 
very low, and the contribution to the shear $\left(s_{s}\right)$ is necessarily even lower.

Other contractional structures (such as the secondary ISB folds at $78^{\bullet}-81^{\bullet}$ E) parallel to the main folds have not been taken into account. These structures, which probably originated through the shortening of an upper thin competent layer in the brittle crustal domain, have amplitudes similar to the depth of the ribbon troughs $(250 \mathrm{~m}$ according to Ghent and Hansen, 1999) that could be formed by the extension of the same layer. Approximate values for $A$ have been estimated in $250 \mathrm{~m}$. The apparent wavelength of these structures is 3 to $10 \mathrm{~km}$. So, the values of the shortening and of the contribution to the shear for these structures are respectively $s=310-3400 \mathrm{~m} ; s_{s}=130-1430 \mathrm{~m}$. Note that this results are higher than those of the main en échelon folds shown in Table 1

\subsubsection{Contribution of the ribbons to the shear}

In order to estimate the contribution of the ribbons to the ISB dextral shearing, it is necessary to know the extension accommodated by these structures. Ghent and Hansen (1998) have developed a method for estimating the ribbon extension. This method is coherent with their hypothesis of ribbons as the product of the extension of a thin brittle crustal domain above the brittle-ductile ransition. These authors assume that the area of the brittle domain of the crust in a cross section perpendicular to the ribbon remains constant during the deformation, so the extension can be calculated on the basis of the ribbon morphology and the depth of the BDT. To determine the BDT depth, Ghent and Hansen (1998) use an analogy with shear-fracture boudinage that permits them to deduce BDT depths from the ribbon spacing only. In order to eliminate the uncertainty of the thickness of the deformed brittle crust, we have devised a simple method for estimating the extension of the ribbons. This method, that does not depend on the depth of the horizontal decollement, is based on constraining the kinematics of the normal faults that outline ribbons. The fault slip can be calculated constraining the morphology of the fault scarp. It is possible to deduce the extension associated with one fault scarp considering two parameters only: the ribbon rough depth $(\boldsymbol{d})$ and the average fault $\operatorname{dip}(\boldsymbol{\beta})$. The horizontal extension associated to one scarp $(E)$ is given by Eq. (5):

$E=\boldsymbol{\alpha} / \tan \boldsymbol{\beta}$.

We have used values of $250-300 \mathrm{~m}$ for $\boldsymbol{d}$, in accordance with estimations by Hansen and Willis (1998) for Fortuna Tessera $(250 \mathrm{~m})$, that have been corroborated by Ghent and Hansen (1999) for Ovda Regio, where $\boldsymbol{d}$ could take higher values. The scarps show dips of $75^{\bullet}-90^{\bullet}$ (Ghent and Hansen, 1999). The very homogeneous value of spacing of these structures implies the existence of a ductile decollement where they take root as listric faults, so the average dip of these normal faults must be lower. In order not to overestimate the amount of extension, a conservative interval of $65^{\circ}$
Table 2

Estimation of the ribbon extension, the shear component and the transtensive component

\begin{tabular}{|c|c|c|c|c|c|c|c|}
\hline$N$ & $\lambda$ & $d$ & $E(\mathrm{~km})$ & $e(\mathrm{~km})$ & $e_{s}(\mathrm{~km})$ & $e_{t}(\mathrm{~km})$ & Elongation (\%) \\
\hline \multirow[t]{4}{*}{170} & 65 & 0.25 & 0.117 & 19.818 & 17.961 & 8.375 & 5.66 \\
\hline & & 0.3 & $\bullet .140$ & 23.782 & 21.554 & 10.051 & 6.79 \\
\hline & 75 & 0.25 & 0.067 & 11.388 & 10.321 & 4.813 & 3.25 \\
\hline & & 0.3 & $\bullet .080$ & 13.665 & 12.385 & 5.775 & 3.90 \\
\hline \multirow[t]{4}{*}{230} & 65 & 0.25 & 0.117 & 26.813 & 24.301 & 11.332 & 7.66 \\
\hline & & $\bullet .3$ & $\bullet .14$ & 32.175 & 29.161 & 13.598 & 9.19 \\
\hline & 75 & 0.25 & 0.067 & 15.407 & 13.964 & 6.511 & 4.40 \\
\hline & & 0.3 & 0.080 & 18.488 & 16.756 & 7.814 & 5.28 \\
\hline
\end{tabular}

to $75^{\bullet}$ for the average dip of these normal listric faults has been used.

After obtaining the value of the extension $(E)$ accommodated by one fault scarp, the extension across the belt can be deduced by counting the scarps $(n)$ (i.e., the alternating dark and bright lineaments). The ribbons show open terminations and sometimes multiple scarps, as is usual with graben morphologies. In the counting, we have considered each multiple scarp as just one scarp, because in this case the offset of the fault is shared by different fault-arms that produce the same depth of the ribbon trough, thereby accommodating the same extension as one simple scarp. Equation (6) expresses the total extension $(e)$ produce by the ribbons in a perpendicular direction to their traces across the belt:

$e=n \frac{\boldsymbol{d}}{\tan \beta}$.

The counting of the scarps has been performed along the en échelon anticline crests because the axial trends of these folds are perpendicular to the ribbon traces, and because the ribbons are better developed and more open in the anticlinal crests than in the inter-anticline valleys. The transverse scarp counting has been performed along two anticline crests, with the results of 170 and 230 ribbons along. The values of total extension (e) calculated using the Eq. (6) are shown in Table 2. Knowing the extension produced and the width of the belt across each transverse, we can calculate $e$ and the fractional elongation.

The extension vector trending perpendicular to the $\mathrm{N}^{\circ} 7^{\circ}$ ribbons has a module that corresponds to $e$, which indicates the amount of displacement of Ovda Regio in an eastnortheastern direction, i.e., opposite to Aino Planitia. This vector can also be divided in two perpendicular components: one parallel to the plateau margin trend and the other one perpendicular to it $(\mathrm{E} \mathbf{q}$ ( (7)). The first one indicates the conribution of the ribbons to the dextral shearing $\left(e_{s}\right)$ (Eq. (8)). The second one represents the ranstenssional component which expresses the extension along a direction normal to the belt $\left(e_{t}\right)$ (Eq. (9)). Both can be calculated using the angle between the ribbon traces and the margin trend $\left(\alpha=65^{\circ}\right)$. All these parameters are shown in Table 2,

$\vec{e}=\vec{e}_{s}+\vec{e}_{t}$, 
$e_{s}=e \cdot \sin \boldsymbol{\alpha}$,

$e_{t}=e \cdot \cos \boldsymbol{\alpha}$

The contribution of the ribbons to the dextral shearing is higher than that of the en échelon folds $\left(e_{s}>s_{s}\right)$. The explanation of this fact is that the contribution of the contractional structures is a minimum estimation, whereas the ribbon contribution is not. Besides, ribbon extension could be increased by the gravitational collapse of the plateau. The minimum total dextral offset produced along the ISP is the addition of the contribution of the ribbons, the main en échelon folds and the secondary folds, and ranges from 10.5 to $31.3 \mathrm{~km}$. Comparing the ranspressional component contributed by the en échelon folds $\left(s_{t}\right)$ with the transtenssional component contributed by the ribbons $\left(e_{t}\right)$, it can be deduced that the ranstenssional component of the ribbons largely compensates the transpressional component of the folds, even taking into account that the transpressional value is underestimated. This means that the ISB has suffered extension perpendicular to its trend, which made the belt 3.2 to $11.3 \mathrm{~km}$ wider during shear deformation.

We have attempted to constrain the conribution of the folds and the ribbons to the dextral displacement along the shear belt, but considering the limited resolution of the Magellan data, a precise estimation of this displacement is not possible, so this computation should be considered semiquantitative. If the ranges estimated for the different variables are correct then we can consider that the real values are inside the error interval of $29.2-10.3 \mathrm{~km}$ for the dexral offset caused by the ribbons and 5-753 m for the clearly underestimated contribution of the folds. These estimations are a minimum but they can give us an idea of the magnitude of the shear zone. It is a wide shear $(400 \mathrm{~km})$ with a low dextral displacement, which explains the small offsets of the individual structures located in this zone of distributed deformation.

\subsection{Outer Shear Belt dextral displacement}

To evaluate the dextral displacement accommodated by the OSB, we have used a prominent structure, located at $11^{\bullet} \mathrm{S}-83^{\bullet} \mathrm{E}$, as a marker. It is a $\mathrm{N} 55^{\bullet}$ sinistral strike-slip fault with pull-apart basins, which we interpret as produced by a NNE-SSW compression occurred before the main dextral shearing tectonic stage (see other strain fields in the OSB). The structure is very straight (a telltale sign of its origin as an strike-slip fault), cut $6 \mathbf{0} \%$ of the OSB, and is covered by the external volcanic units of Aino Planitia (Fig. 4). These features make this structure a good strain marker of the $60 \%$ northern band of the OSB. The large strike-slip faults typical of the OSB produce a dextral offset of the marker (Fig. 3b). This offset increases toward the south of the belt. The total dextral offset (measured in the shearing direction) recorded by this structure is $12 \mathrm{~km}$. Taking into account that this fault affects only $60 \%$ of the OSB width, that estimation is clearly a minimum. If we assume that the dexal displacement in the southern $40 \%$ of the OSB is similar in magnitude to the estimated offset in the northern $60 \%$, then the total displacement for the OSB would be $2 \mathrm{~km}$. But taking under consideration that the recorded strain is not homogeneous, and also that it increases to the south as the marker indicates, this extrapolated offset should also be considered as a minimum estimation.

\section{Discussion and conclusions}

For the first time several clear long brittle-style faults have been described and interpreted as strike-slip faults because of their internal Riedel fracture patterns, though some other instances of strike-slip tectonics on the venusian surface were described before (Hansen, 1992; Watters, 1992; Willis and Hansen, 1996; Koenig and Aydin, 1998; Davis and Ghail, 1999; Tuchwell and Ghail, 2003). It is important to stress that these structures and the tectonic evolution we have found in the studied area do not fit into the general models proposed so far to explain the continental plateaux formation, in general, and the tectonic evolution of $\mathrm{vda}$ Regio, in particular. The most difficult feature to integrate into the current models is the transcurrent tectonic regime in the Outer and Inner Shear Belts at the Southern Margin of Cen ral Ovda Regio, but other geological features are neither coherent with such models, like the temporal relationships between structures, ribbons and folds, and the orientation of these structures in relation with the general plateau geometry. In order to envisage an evolutionary and geodynamic explicative model we need to take into account several important structural features, provided by the previous structural analysis

The tectonic history recorded on the surface of the southern margin of Central ovda that has been inferred from the structural analysis is complex and contains different tectonic stages with distinct deduced stress fields that follow one another in time. The first tectonic stage shows evidence of a maximum NNE-SSW to NE-SW compressional direction, giving rise to $\mathrm{N} 110^{\bullet}$ ridges (folds) associated to perpendicular extensional paired conjugate faults (ribbons) trending $\mathrm{N} 25^{\circ}$ in the $\mathrm{OSB}$ and $\mathrm{N} 30^{\circ}-55^{\circ}$ in the ISB, and some N55 sinistral strike-slip faults with associated pullapart basins in the OSB (Fig. 7). The second tectonic stage, a regional dextral strike-slip tectonism, is the main tectonic period of crustal deformation in this southern border of Central Ovda Regio. The two major crustal shear belts were formed In this stage, with a dense pattern of ribbons and en échelon folds (ridges) coherent with a $\mathrm{N} 167^{\bullet}$ compressional direction and a distributed right lateral wrench deformation. In the ISB the deformation probably started prior to the one in the OSP, where dextral shear continued producing the great brittle-style strike-slip faults and sigmoidal ridges which postdate the ISB structures. These faults deform the older volcanic units in Aino Planitia at the border of the OSB, that flooded part of this belt from the South. 
It is thus possible to infer that the tectonic activity in the OSB started before the flooding of lavas and continued after the formation of regional lava plains. The global resurfacing event that generated the regional volcanic plains has been dated by crater counting in $500 \mathrm{Ma}$ by Schaber et al. (1992), Strom et al. (1994) and Turcotte et al. (1999). Taking into account modified craters other authors (Phillips et al., 1992; Herrick and Phillips, 1994; Phillips and Hansen, 1998; Herrick and Sharpton, 1999) think that this process took place more slowly, from 700 to $500 \mathrm{Ma}$. Anyway, assuming that these lavas are in fact associated with the hypothesized global resurfacing event, it can be pointed out that the development of the main shear deformation in the OSP took place in the interval of 700-500 myr; but it could had as well started before this period, or ended after it, or both. A last period of tectonic activity producing a new set of ribbons and perpendicular ridges has been detected on one late intratessera plain built into a subcircular flooded depression north of the ISB. This particular structural pattern seems to be caused by a tectonic regime with a shortening direction trending NE-SW. Finally we have considered the possibility of an extensional reactivation of the OSB caused by the Ixel and Kuanja chasmata (Bleamaster and Hansen, 2004), to which could be attributed the origin of some pit chains developed along the eastern area of the belt.

In trying to devise the driving forces that deformed these shear belts, we find serious problems in the building up of a geodynamic explanation for this succession of tectonic stages within the framework of current models about venusian plateaux formation. The upwelling model (Ghent and Hansen, 1999) cannot explain the structural information, even taking under consideration a complex upwelling model for Ovda Regio, with different hot spots successively activated (Mestre et al., 1998). The first tectonic stage observed (NE-SW to NNE-SSW shortening direction) is coherent with that upwelling model if the spreading center is located in the middle of Eastern Ovda, but the main dextral shear tectonic stage cannot be explained by this hot spot.

The upwelling model for the crustal plateaux formation predicts concentric compressive belts around the spreading center assuming a homogeneous and isotropic initial medium which is hardly ever the case. But even considering that the initial anisotropies and inhomogeneities could change locally the radial distribution of the compressive stresses, to generate a shear belt of this magnitude disposed along the margin trend with a compressive stress oriented near perpendicular to it, is a kinematic impossibility. On the other hand, the structural analysis performed in this work has demonstrated, using two different criteria (width of ribbon roughs on fold crest and limbs, and ribbons crossing post-folding in atessera plains), that at least some of the ribbons have been developed postdating the folds, something that contradicts an important assumption of the upwelling model. Furthermore, the minimum total offset estimated for the shear belts ranges from 30.5 to $51.3 \mathrm{~km}(10.5-31.3 \mathrm{~km}$ for the ISB and $20 \mathrm{~km}$ for the OSB), which implies a con- siderable horizontal displacement, started before and partially accomplished after the global resurfacing process. This seems to conradict the most accepted viewpoint that estimates the horizontal movements as highly restricted during the period of time after the global resurfacing process (Phillips and Hansen, 1998). Considering the opposite hypothesis, the downwelling model proposed by Bindschadler et al. (1992), it can be concluded that this model cannot explain the observed ranscurrent margin either, because it also predicts concentric compressive belts in the margins of the non-subducted plateau located above the cold spot. If the hypothesis proposed by Mestre et al. (1998) were correct, a second tectonic stage should be observed in the southern border, characterized by a WNW-ESE or NW-SE shortening direction ransmitted from the Western ovda spreading center, but this strain field has not been observed. The second tectonic stage inferred from the structural analysis for ISB and OSB corresponds to a different NNW-SSE shortening direction, as it has been described above. Thereby, it can be deduced that the succession of upwelling centers proposed is not supported by our detailed structural analysis, notwithstanding their cen place as the most accepted theory for the origin of Ovda Regio so far

So, it is necessary to implement a new model for driving forces able to explain the dextral crustal shearing along the southern margin of Central ovda Regio, simultaneously with the flooding of the regional plains. We have found a possible explanation observing the northern margin of Central Ovda (Romeo et al., 2003). This margin shows a fold belt rending ENE-WSW with perpendicular extensional fractures (simple fractures, ribbons and graben). This fold belt, which has been interpreted as a collisional belt (King et al., 1998; Tuckwell and Ghail, 2002) can be explained as formed by a NNW-SSE compression, perpendicular to the plateau margin trend. It is highly significant that the contractional and extensional structures that appear in the northern margin of Central Ovda have their equivalents in the southern margin of Eastern Ovda, whose trend is different (WNW-ESE) but have a consistent pattern of ribbons and folds and a coherent NNW-SSE shortening direction: probably that means there was a unique stress field. Thereby, a good explanation for the dexal shear tectonics observed in the southern margin of Central ovda is that it was produced by a stress field ransmitted from the collisional zone in the north (Fig. 6). Consequently, the shear tectonism described in this paper can be considered a transcollisional transcurrent zone, similar to the strike-slip tectonics that appears in the foreland of Earth collisional orogens, like for example in the Himalayas and Tibet collisional area (Vaunay and Steck, 1995). As in Ovda Regio, in this example we can find, as we go from the lower plate towards the transcollisional zone and the collisional fold belt, the high plateau with thickened crust and the transcollisional zone with wrench faults (Fig. 6). In this way Eastern Ovda Regio (where Central Ovda is included) nuns as an independent portion of thickened crust, which implies that the deformation is concentrated along the margins. 
Under a compressive stress transmitted from the collision of Niobe Planitia and Ovda Regio plateau, with a resultant NNW-SSE horizontal shortening, Eastern ovda moved towards the SSE, causing the dextral shear deformation in the southern margin.

The strike-slip interpretation of the southern margin agrees with the new hypothesis proposed by Tuckwell and Ghail (2002) for Eastern Ovda formation. These authors consider that the collision of the northern margin was simultaneous with an upwelling flow in the middle zone of Eastern Ovda. In fact this model predicts with considerable precision the orientations we have observed on the main tectonic structures and the shear tectonism in the southern margin, though the presence of some ribbons postdating the folds in the plateau interior is difficult to explain by the upwelling flow in the center of Eastern Ovda.

The presence of two different shear belts in the southern border can be explained by taking into account their distinct rheological behavior, controlled by the crustal thickness. The ISB is developed by distributed deformation in a thicker crust. The thickness decreases towards the South, whereas the OSB was formed in a thinner crust, which is, on the other hand, just a bit thicker than the crust of the regional volcanic plains.

Periodical catastrophic subduction events have been proposed as a mechanism of Venus cooling. This hypothesis is supported by the random distribution of impact craters on the venusian surface (Turcotte, 1995, 1996; Turcotte et al., 1999). If the flooding of the regional volcanic plains took place during the last putative subductive event, could the northern collisional margin of Eastern ovda be caused by a subduction zone? Could the strike-slip tectonism of the southern margin be induced by the last subductive event? That interpretation could explain the fact that the regional volcanic plains of Aino Planitia were emplaced during the strike-slip movement.

\section{References}

Ahlgren, S.G., 2001. The nucleation and evolution of Riedel shear zones as deformation bands in porous sandstone. J. Struct. Geol. 23, 1203-1214.

Bindschadler, D.L., Schubert, G., Kaula, W.M., 1992. Coldspots or hotspots? The origin of plateau-shaped highlands on Venus. J. Geophys. Res. 97, 13459-13532.

Bleamaster, L.F., Hansen, V.L., 2001. The Kuanja/Vir-Ava Chasmata: a coherent intrusive complex on Venus. Lunar Planet. Sci. 32. Abstract 1316.

Bleamaster, L.F., Hansen, V.L., 2004. Effects of crustal heterogeneity on the morphology of chasmata, Venus. J. Geophys. Res. 109. E2004.

Burg, J.P., Podladchikov, Y.U., 1999. Lithospheric scale folding, numerical modelling and application to the Himalayan syntaxes. J. Earth Sci. 88, 190-200

Campbell, B.A., Arvidson, R.E., Shepard, M.K., Bracket, R.A., 1997. Remote sensing of surface processes. In: Bougher, S.W., Hunten, D.M., Phillips, R.J. (Eds.), Venus II: Geology, Geophysics, Atmosphere and Solar Wind Environment. Univ. of Arizona Press, Tucson, pp. 503-525.

Connors, C., 1995. Determining heights and slopes of fault scarps and other surfaces on Venus using Magellan stereo radar. J. Geophys. Res. 100 (E7), 14361-14381
Davis, A.M., Ghail, T.H., 1999. An extended strike-slip zone in Aphrodite Terra. Lunar Planet. Sci. 30. Abstract 1330.

Davis, G.H., Bump, A.P., Garcia, P.E., Ahlgren, S.G., 2000. Conjugate Riedel deformation band shear zones. J. Struct. Geol. 22, 169-190

Farr, T.G., 1993. Radar interactions with geologic surfaces. In: Ford, J.P., Plaut, J.J., Wietz, C.M., Farr, T.G., Senske, D.A., Stofan, E.R., Michaels, G., Parker, T.J. (Eds.), Guide to Magellan Image Interpretation. NASA JPL, Pasadena, pp. 45-56.

Faulkner, D.R., Lewis, A.C., Rutter, E.H., 2003. On the internal structure and mechanics of large strike-slip fault zones, field observations of the Carboneras Fault in southeastern Spain. Tectonophysics 367 (3-4), 235-251.

Ferill, D.A., Sims, D., Stamatakos, J.A., Rehe, B., Morris, A.P., 1997. Role of a ductile detachment horizon in the development of pull-apart basins in physical analog models. Annual Meeting Abstracts-AAPG and Society of Economic Paleontologists and Mineralogists 6. Abstract 35.

Ghent, R.R., Hansen, V.L., 1997. Structural analysis of Central and Eastern Ovda Regio, Venus. Lunar Planet. Sci. 28, 409-410.

Ghent, R.R., Hansen, V.L., 1998. Geometrical analysis of shear-fracture ribbøns in Ovda Regio, Venus. Lunar Planet. Sci. 29. Abstract 1638.

Ghent, R.R., Hansen, V.L., 1999. Structural and kinematic analysis of Eastem Ovda Regio, Venus: implications for crustal plateau formation. Icarus 139, 116-136

Gilmore, M.S., Collins, G.C., Ivanov, M.A., Marinangeli, L., Head, J.W., 1998. Style and sequence of extensional structures in Tessera terrain, Venus. J. Geophys. Res. 103, 16813-16840.

Gordon, R.G., Cox, A., O’Hare, S., 1984. Paleomagnetic Euler poles and the apparent polar wander and absolute motion of North America since the Carboniferous. Tectonics 3, 499-537.

Hansen, V.L., 1992. Regional non-coaxial deformation on Venus: evidence from Western Itzpapalotl Tessera. Lunar Planet. Sci. 23, 478-479.

Hansen, V.L., Willis, J.J., 1995. Structural analysis of a sampling of Tesserae: implications for Venus geodynamics. Icarus 123, 296312.

Hansen, V.L., Willis, J.J., 1997. Ribbon terrain formation and implications for lithosphere evolution, Venus. Lunar Planet. Sci. 28. Abstract 1424.

Hansen, V.L., Willis, J.J., 1998. Ribbon terrain formation, Southwestem Fortuna Tessera, Venus: implications for lithosphere evolution. Icarus 132, 321-343.

Hansen, V.L., Willis, J.J., Banerdt, W.B., 1997. Tectonic overview and synthesis. In: Bougher, S.W., Hunten, D.M., Phillips, R.J. (Eds.), Venus II. Univ. of Arizona Press, Tucson, pp. 797-844.

Hansen, V.L., Banks, B.K., Ghent, R.R., 1999. Tessera terrain and crustal plateaus, Venus. Geology 27, 1075-1078.

Herrick, R.R., Phillips, R.J., 1994. Effects of the venusian atmosphere on incoming meteoroids and the impact crater population. Icarus 112, 253281

Herrick, R.R., Sharpton, V.L., 1999. There are a lot more embayed craters on Venus than previously thought. Lunar Planet. Sci. 30. Abstract 1696.

Ivanov, M.A., Head, J.W., 1996. Tesseraterrain in Ovda Regio, Venus: preliminary results of a geologic mapping traverse. Lunar Planet. Sci. 27, $591-592$

Ivanov, M.A., Head, J.W., 1999. Ridge-Ribben age relationships in Northeast Ovda Regio, Venus. Lunar Planet. Sci. 30. Abstract 1232.

Kim, Y.-S., Peacock, D.C.P., Sanderson, D.J., 2003. Mesoscale strike-slip faults and damage zones at Marsalforn, Gozo Island, Malta. J. Struct. Geol. 25, 793-812

King, R.L., Cruz, J., Grosfils, E.B., Gilmore, M.S., Reinen, L.A., Kozak, S.J., 1998. Structural deformation of Northern Ovda Regio, Venus: implications for venusian tectonics. Lunar Planet. Sci. 29. Abstract 1209.

Koenig, E., Aydin, A., 1998. Evidence for large-scale strike-slip faulting on Venus. Geology 26 (6), 551-554.

Mandal, N., Chakraborty, C., Kumar, S.S., 2000. Boudinage in multilayered rocks under layer-normal compression, a theoretical analysis. J. Struct. Geol. 22, 373-382.

Mestre, E., Mason, P., Pinet, P., 1998. Evolution stages of Ovda Regio from structural history: first results. Lunar Planet. Sci. 29. Abstract 1603. 
Phillips, R.J., Hansen, V.L., 1998. Geological evolution of Venus: rises, plains, plumes and plateaus. Science 279, 1492-1497.

Phillips, R.J., Herrick, R.R., Grimm, R.E., Raubertas, R.F., Sarkar, I.C., Arvidson, R.E., Izenberg, N., 1992. The resurfacing history of Venus, constraints from impact crater distribution. Lunar Planet. Sci. 23, 10651066

Plaut, J.J., 1993. Stereo imaging. In: Ford, J.P., Plaut, J.J., Wietz, C.M., Farr, T.G., Senske, D.A., Stofan, E.R., Michaels, G., Parker, T.J. (Eds.), Guide to Magellan Image Interpretation. NASA JPL, Pasadena, CA, pp. 33-43.

Ramsay, J.G., Huber, M.I., 1987. The Techniques of Modern Structural Geology: Folds and Fractures, vol. 2. Academic Press, Oxford, England.

Romeo, I., Capote, R., Anguita, F., 2003. Dextral shear deformation belt on the southern margin of Central Ovda Regio: preliminary results. Lunar Planet. Sci. 34. Abstract 1078.

Schaber, G.G., Strom, R.G., Moore, H.J., Soderblom, L.A., Kirk, R.L., Chadwick, D.J., Dawson, D.D., Gaddis, L.R., Boyce, J.M., Russell, J., 1992. Geology and distribution of impact craters on Venus: what are they telling us? J. Geophys. Res. 97 (E8), 13257-13301.

Strom, R.G., Schaber, G.G., Dawson, D.D., 1994. The global resurfacing of Venus. J. Geophys. Res. 99, 10899-10926.
Tchalenko, J.S., 1970. Similarities between shear zones of different magnitudes. Geol. Soc. Am. Bull. 81, 1625-1640.

Tuckwell, G.W., Ghail, R.H., 2002. The deformation of Eastern Ovda Regio: collision and complexity. Lunar Planet. Sci. 33. Abstract 1566.

Tuckwell, G.W., Ghail, R.H., 2003. A $400 \mathrm{~km}$ scale strike-slip zone near the boundary of Thetis Regio, Venus. Earth Planet. Sci. Lett. 211, 4555 .

Turcotte, D.L., 1995. How does Venus lose heat? J. Geophys. Res. 100 (E8), $16931-16940$

Turcotte, D.L., 1996. Magellan and comparative planetology. J. Geophys Res. 101 (E2), 4765-4773.

Turcotte, D.L., Morein, G., Roberts, D., Malamud, B.D., 1999. Catastrophic resurfacing and episodic subduction on Venus. Icarus 139, 49-54.

Twiss, R.J., Moores, E.M., 1992. Structural Geology. Freeman, New York.

Vaunay, J.C., Steck, A., 1995. Tectonic evolution of the High Himalaya in Upper Lahul (NW Himalaya, India). Tectonics 14 (2), 253-263.

Watters, T.R., 1992. System of tectonic features common to Earth, Mars and Venus. Geology 20, 609-612.

Willis, J.J., Hansen, V.L., 1996. Conjugate shear fractures at Ki corona southeast Parga Chasma, Venus. Lunar Planet. Sci. 27, 14431444. 